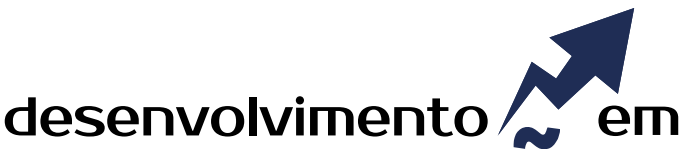 QUESTÃO
}

\section{Educação Profissional e Tecnológica para o Desenvolvimento Regional no Brasil: A Atuação do Instituto Federal de Santa Catarina}

http://dx.doi.org/10.21527/2237-6453.2020.52.216-232

Recebido em: 20/10/2018

Aceito em: 28/2/2020

Eliane Salete Filippim, ${ }^{1}$ Rafael Klein Moreschi ${ }^{2}$

\begin{abstract}
RESUMO
O objetivo deste artigo foi analisar a atuação dos Institutos Federais de Educação, Ciência e Tecnologia (IFs) e a sua adesão ao papel da Educação Profissional e Tecnológica (EPT) de promoção do desenvolvimento regional. Para tal foi utilizada, como recorte analítico, a região do Oeste de Santa Catarina, sul do Brasil e, como foco, o estudo do caso do Instituto Federal de Santa Catarina (IFSC), representado pelos três campi que constituíram as unidades de análise do estudo: Chapecó, São Miguel do Oeste e Xanxerê. Para efetivação da pesquisa foi adotada abordagem predominantemente qualitativa, valendo-se de investigação bibliográfica, documental e de campo (entrevistas, observação e questionários). A Análise de Conteúdo foi utilizada como técnica de análise e os dados foram triangulados entre si e cotejados com a teoria. Os resultados da pesquisa apontam que a atuação dos IFs os distancia do papel para o qual foram criados, reduzindo sua contribuição à qualificação de mão de obra para o mercado de trabalho, sobretudo por meio da Educação Profissional Técnica de Nível Médio (EPTNM). Verificou-se também que a legislação educacional brasileira, inclusive o Plano de Desenvolvimento Institucional (PDI) do IFSC trata a EPT como importante política pública voltada ao desenvolvimento regional e do país. A cultura interna da instituição, no entanto, que tem suas raízes nos preconceitos históricos atribuídos a essa modalidade educacional no Brasil, não permite que o IFSC se consolide como ferramenta de aplicação dessa política pública.
\end{abstract}

Palavras-chave: Educação profissional e tecnológica. Desenvolvimento regional. Instituto Federal de Educação, Ciência e Tecnologia.

\section{PROFESSIONAL AND TECHNOLOGICAL EDUCATION FOR REGIONAL DEVELOPMENT IN BRAZIL: THE WORK OF THE FEDERAL INSTITUTE OF SANTA CATARINA}

\section{ABSTRACT}

The objective of this article was to analyze the work of the Federal Institutes of Education, Science and Technology (IFs) and their adherence to the role of Professional and Technological Education (EFT) in promoting regional development. For this purpose, the Western region of Santa Catarina, Southern Brazil, was used as an analytical cutout, and as a focus, the case study of the Federal Institute of Santa Catarina (IFSC), represented by the three campuses that constituted the study analysis units: Chapecó, São Miguel do Oeste and Xanxerê. To carry out the research, a predominantly qualitative approach was adopted, using bibliographic, documentary and field research (interviews, observation and questionnaires). Content Analysis was used as an analysis technique and the data were triangulated with each other and collated with the theory. The results of the research indicate that the work of the IFs distances them from the role for which they were created, reducing their contribution to the qualification of labor for the labor market, especially through the Medium Level Technical Professional Education (MTPE). It was also verified that the Brazilian educational legislation, including the Institutional Development Plan (PDI) of the IFSC, treats the TPE as an important public policy focused on regional and country development. However, the institution's internal culture, which has its roots in the historical prejudices attributed to this educational modality in Brazil, does not allow the IFSC to be consolidated as an application tool of this public policy.

Keywords: Professional and technological education. Regional development. Federal Institute of Education, Science and Technology.

\footnotetext{
${ }^{1}$ Doutora em Engenharia de Produção e Sistemas pela Universidade Federal de Santa Catarina (UFSC). Professora da Universidade do Oeste de Santa Catarina (Unoesc). http://lattes.cnpq.br/0360830302435021. https://orcid.org/0000-0003-4064-1059. eliane.filippim@unoesc.edu.br

${ }^{2}$ Mestre em Administração pela Universidade do Oeste de Santa Catarina (Unoesc). Servidor da Universidade Federal da Fronteira Sul (UFFS). http://lattes.cnpq.br/7610736948524000. https://orcid.org/0000-0001-8189-3194. rafael.moreschi@uffs.edu.br
} 
A Rede Federal de Educação Profissional, Científica e Tecnológica (RFEPCT), composta, prioritariamente, pelos Institutos Federais de Educação, Ciência e Tecnologia (IFs), passou por uma grande expansão no período de 2003 a 2014, podendo-se constatar que no período de 1909 a 2002 foram instaladas 140 escolas técnicas no Brasil, que atendiam 120 municípios. Já entre 2003 e 2010 o Ministério da Educação (MEC) estabeleceu 214 escolas técnicas, ampliando o número para 354 e o número de municípios atendidos para 321. Por fim, entre 2011 e 2014 foram mais 208 novas unidades, totalizando 562 escolas técnicas instaladas e 512 municípios atendidos (BRASIL, 2017c). Vista anteriormente como educação de segunda linha e voltada às classes menos favorecidas, a educação profissional ganhou força no Brasil (MELLO; MELO; MELLO FILHO, 2016), tendo-Ihe sido atribuído importante papel na promoção do desenvolvimento regional, conforme os principais dispositivos legais que tratam do tema, a saber: Lei 11.892/2008, Resolução CNE/CEB 6/2012 e Lei 13.005/2014.

Neste contexto, a pergunta-problema que orientou esta pesquisa foi: A atuação dos IFs é aderente ao papel da Educação Profissional e Tecnológica (EPT) de promoção do desenvolvimento regional? Uma das justificativas para a realização deste estudo está associada a que "o governo tem responsabilidades de importância crítica por fatores fundamentais, como os sistemas educacionais de nível elementar e secundário" (PORTER, 1999, p. 198). A EPT abrange os cursos de: formação inicial e continuada ou qualificação profissional, Educação Profissional Técnica de Nível Médio (EPTNM), de Graduação e de Pós-Graduação, sendo justamente a EPTNM a modalidade foco dos IFs (INEP, 2011).

Neste ponto cabe destacar que o Ensino Médio brasileiro sofre crise de identidade, problemática, que decorre da dupla função atribuída a este nível de formação, pois ele deveria dar conta de preparar o aluno para a continuidade dos estudos no Ensino Superior e, ao mesmo tempo, para uma profissão (DEITOS; LARA, 2016). No Brasil, entretanto, o Ensino Médio visa unicamente a preparar o aluno para continuidade dos estudos no Ensino Superior, negligenciando sua profissionalização. Tendo em vista a realidade socioeconômica brasileira, em que grande parte dos filhos das classes populares precisa trabalhar antes dos 18 anos de idade, é imprescindível que tal proposta de ensino seja repensada, a fim de possibilitar ao aluno não apenas o acesso ao Ensino Superior, mas também ao mundo do trabalho (MOURA, 2013).

Com a promulgação da Lei 13.415, de 2017, que trata da reforma do Ensino Médio, parece que o governo deu alguns passos nessa direção, uma vez que, entre outras alterações, promoveu a inclusão da formação profissional ao currículo deste nível de ensino, no entanto ainda é cedo para qualquer prognóstico a respeito dessa reforma, pois de acordo com a própria Resolução CNE/CP 2/2017, que instituiu a Base Nacional Comum Curricular (BNCC), na qual tal reforma está pautada, as instituições ou redes de ensino têm prazo até o início do ano letivo de 2020 para adequarem seus currículos à BNCC.

Aliado a esta questão do Ensino Médio, evidencia-se que a EPT ainda não está suficientemente difundida no Brasil, o que leva os IFs a enfrentarem problemas de falta de alunos e alta evasão, sobretudo nos cursos técnicos de nível médio nas modalidades concomitante e subsequente, pois muitos estudantes não têm interesse em frequentar um curso profissionalizante, posto que no Brasil se difundiu a ideia de que o curso 
superior é o único caminho para uma formação sólida. Esse fato tem origem histórica, quando o sistema de ensino profissional e o sistema de ensino superior tinham diferentes objetivos culturais e sociais, constituindo-se, por isso mesmo, em instrumentos de estratificação social. A escola profissional servia à classe popular, enquanto que a escola superior servia às classes mais abastadas (TAKAHASHI, 2010). Ainda restam alguns traços desse entendimento na sociedade, o que gera discriminação à EPT.

Outra justificativa social da relevância deste estudo é que a região eleita para a pesquisa, o Oeste de Santa Catarina, sul do Brasil, contempla indicadores de desenvolvimento que se encontram abaixo da média estadual, observando-se que as disparidades ficam mais evidentes quando esta região é comparada às regiões litorâneas do Estado (BERNARDY et al., 2016). Nessa perspectiva, enfatiza-se a necessidade do desenvolvimento regional e de pesquisas voltadas ao seu estudo. Além disso, este tema atende também à demanda científica e à agenda de pesquisa. Para constatar tal necessidade desenvolveu-se estudo em bases de dados da área da gestão Spell, SciELO e Ebsco, considerando o período de 2005 a 2015. Os termos de busca utilizados foram "educação profissional" e "desenvolvimento regional", ambos pesquisados em cada uma das referidas bases.

Destaca-se que ao se pesquisar os termos de modo separado, foram obtidos 3.733 resultados para desenvolvimento regional e 2.080 para educação profissional, o que oferece uma primeira impressão de que tais termos já estão suficientemente discutidos. Ao realizar a pesquisa com os dois termos conjugados, porém, os resultados obtidos foram mais modestos (47 artigos), o que revela que, apesar de a educação profissional ser objeto da pesquisa científica, número menor de estudos a abordam em relação ao desenvolvimento regional. Estas 47 publicações encontradas, em sua maioria, abordam questões de ordem educacional, observando-se carência de estudos com base na ótica da gestão. Aqui se encontrou a lacuna científica sobre a qual se focou a pesquisa, ao abordar, sob a ótica da gestão pública, a educação profissional para o desenvolvimento regional.

\section{EDUCAÇÃO PROFISSIONAL E TECNOLÓGICA PARA O DESENVOLVIMENTO REGIONAL}

Embora a abordagem do desenvolvimento regional venha adquirindo importância no meio acadêmico e fora dele, trata-se de um debate que envolve questões complexas, portanto, existem poucos consensos entre pesquisadores e gestores. Não se pode negar, entretanto, que da década de 90 para cá, intensificaram-se as discussões sobre regionalização, tanto no contexto da academia quanto no da sociedade, mais especificamente na esfera pública, o que indica que o desenvolvimento regional vem se tornando um desafio à administração pública, uma vez que as esferas regionais passam a ser mais demandadas. Nesse sentido, a organização territorial/regional deixou de ter um papel passivo (FEGER et al., 2010).

Para Boisier (1996, p. 33), o desenvolvimento regional "trata-se de um processo de mudança social sustentada que tem como finalidade última o progresso permanente da região, da comunidade regional e de cada indivíduo residente nela". Já Sotarauta (2005) descreve que o processo de desenvolvimento regional passa por agenda de mobilização de recursos e atores que proporcionam a aprendizagem e troca de conhecimento. 
Importante destacar, ainda, que o processo de desenvolvimento regional compreende crescente esforço das sociedades locais na formulação de suas próprias estratégias, com o intuito de discutir as questões centrais da complexidade contemporânea e que tornem a região o sujeito de seu próprio processo de desenvolvimento (DALLABRIDA, 2000). Nessa perspectiva, Filippim et al. (2014, p. 13) destacam que "[...] o território local/regional, por meio da cooperação entre seus atores, deve decidir o estilo de desenvolvimento que quer para si".

Considera-se que o conceito de desenvolvimento regional aplica-se adequadamente à realidade brasileira, uma vez que o debate sobre o desenvolvimento no Brasil, que se caracteriza por ser um país extenso e possuir elevadas desigualdades sociais e regionais, exige atenção particular às questões espaciais. As ações desencadeadas em favor da população devem ter endereço e estar mais atreladas aos lugares nos quais os problemas se manifestam. Do contrário ocorre dispersão de esforços, ineficiência no emprego dos meios e ineficácia na obtenção dos resultados almejados. O espaço representa elemento de referência para se ampliar a efetividade das políticas de promoção do desenvolvimento no seu papel de reduzir desigualdades e equiparar as condições básicas da cidadania (THEIS; GALVÃO, 2012).

Tal conceito, no entanto, tornou-se prática no Brasil apenas a partir de 2003, quando se iniciaram as discussões referentes à Política Nacional de Desenvolvimento Regional. Até final de 2003 as políticas de desenvolvimento regional eram traçadas prioritariamente considerando macrorregiões do país, isto é, áreas vastas que não necessariamente guardavam homogeneidade e similaridades. Para atenuar esta problemática o Ministério da Integração Nacional (MI), órgão do governo federal brasileiro, divulgou um documento intitulado Política Nacional de Desenvolvimento Regional. Nele foi delineada uma nova abordagem para as ações da administração federal relacionadas com o desenvolvimento regional e com o enfrentamento das desigualdades regionais. Nesse documento foi definido que as mesorregiões deveriam ser privilegiadas como a escala preferencial de intervenção para as ações relacionadas às políticas de desenvolvimento (BANDEIRA, 2004).

A ideia era consolidar os Programas Mesorregionais dentro de agenda preestabelecida de ações, que incluía, prioritariamente: infraestrutura clássica de média e pequena escala, apoio à inovação e suas práticas em arranjos produtivos locais, educação profissional, apoio à ampliação dos ativos relacionais e oferta de crédito para as unidades produtivas. Surge, nesse ponto, uma aproximação entre as temáticas centrais deste estudo, em que o Ml apresenta a educação profissional como política pública necessária para a consolidação do processo de desenvolvimento regional, mencionando, inclusive, a necessidade de adequações dessa modalidade de educação às especificidades de cada região, ou seja, planejar e gerir essa política pública a partir do território, o que mais tarde se tornaria um dos principais objetivos dos IFs.

Com base nessa premissa do desenvolvimento regional e, principalmente, com a finalidade de atenuar o atraso educacional do Brasil em relação aos países desenvolvidos, diversas políticas públicas educacionais têm sido formuladas e instituídas no âmbito nacional, entre elas a de expansão da RFEPCT, visando, sobretudo, a uma maior democratização do acesso. Tal investimento é imprescindível, visto que a educação é uma das principais vias para superar o atraso social dos países da América Latina e poucos 
esforços em matéria de política pública têm um retorno tão evidente quanto o de capacitar as gerações mais jovens e dar-lhes as ferramentas para aproveitar as oportunidades que oferecem uma economia mais moderna e diversa (MORENO, 2011). Importante destacar que a EPT não se configura como política pública somente pela sua fonte de financiamento, mas, especialmente, por seu compromisso com o todo social (PACHECO, 2011).

Nem sempre, contudo, a EPT foi vista como parte do processo integral de formação e comprometida com o todo social, pois nas primeiras vezes que surgiu como política pública foi pelo viés (reducionista) da formação para o mercado de trabalho (PACHECO, 2011). A Lei de Diretrizes e Bases da Educação Nacional Brasileira (LDB/96) colocou-se como tentativa de superar os enfoques de uma educação apenas voltada à qualificação para o mercado de trabalho, dispondo como diretriz básica que ela precisa ser integrada às diferentes formas de educação, ao trabalho, à ciência e à tecnologia, com vistas ao permanente desenvolvimento do país (BRASIL, 1996). Na prática, a LDB passou a exigir que os alunos do Ensino Médio passassem a ter um mesmo conjunto de disciplinas obrigatórias que poderiam ser complementadas, mas não substituídas, pela formação profissional (SCHWARTZMAN; CASTRO, 2013), ou seja, embora tenha reconhecido a importância da educação profissional e dado destaque a ela, a LDB tornou mais longo o caminho de quem optasse por essa formação, isso porque essa modalidade educacional faz parte de um sistema paralelo ao regular (OLIVEIRA; VIANA, 2012).

Evidencia-se que o principal lócus de atuação da educação profissional brasileira é o Ensino Médio. Importante aprofundar aqui a discussão já iniciada na introdução, quanto à crise de identidade do Ensino Médio brasileiro, que conforme apregoam Gomes, Vasconcelos e Coelho (2018), delimita-se entre duas pontas: o Ensino Fundamental e a Educação Superior, o que torna, de fato, bastante complexo o estabelecimento de identidade própria a esse nível de ensino, pois envolve preparos vitais para seus alunos se posicionarem na sociedade, entre eles o intelectual (propedêutico), o social (cidadania) e o profissional (mundo do trabalho), ressaltando-se que ao buscar atender a todas essas frentes acabou por não conseguir fazê-lo de forma satisfatória, culminando com o estabelecimento de "um currículo único pretencioso, superficial e inviável, e totalmente orientado para a preparação para o Exame Nacional do Ensino Médio (Enem), estreita porta de acesso ao Ensino Superior público" (SCHWARTZMAN, 2018, p. 15).

Adiciona-se a esta discussão a questão da dualidade estrutural que está atrelada ao conceito de escola como fator de estratificação social, ou seja, a existência de dois caminhos a serem seguidos: o Ensino Médio (formação geral) que serviria aos ricos, para prepará-los para a continuidade dos estudos no Ensino Superior e o Ensino Médio profissionalizante, que serviria aos pobres, a fim de prepará-los para o mercado de trabalho (DEITOS; LARA, 2016). A solução para essa dualidade seria a instituição do Ensino Médio integrado, isto é, que integre a formação geral à formação profissional (SECRETARIA..., 2004), uma vez que com a necessidade premente de desenvolvimento do país, torna-se urgente ampliar as políticas públicas que atendam aos anseios de jovens que desejam se qualificar para o mundo do trabalho (OLIVEIRA; ESCOTT, 2015). Esta não é a realidade que se observa no Brasil, uma vez que o Ensino Médio visa unicamente a preparar para o acesso ao Ensino Superior e, diante disso, a educação profissional permanece atrofiada no país (SCHWARTZMAN; CASTRO, 2013). 
A promulgação da Lei 13.415/2017 parece buscar mudar essa realidade no cenário brasileiro, pois, entre outras alterações, promove a inclusão da educação profissional no currículo do Ensino Médio (BRASIL, 2017a), no entanto ainda não se pode fazer qualquer análise dessa reforma no Ensino Médio, uma vez que a lei é recente, assim como a aprovação da BNCC. O cenário observado é de que a educação profissional ainda é trabalhada de forma tímida para contribuir de maneira mais efetiva com o desenvolvimento regional. Nesse sentido, observa-se que a educação profissional tem sido reclamada por segmentos importantes da sociedade como uma política pública estratégica ao desenvolvimento do país (MACHADO, 2011). Como resposta a esta demanda da sociedade destaca-se a expansão da RFEPCT.

Neste contexto inserem-se os IFs, instituições que majoritariamente compõem a RFEPCT e que surgem com uma proposta diferenciada para trabalhar a educação profissional. Não se trata de preparar o cidadão para servir aos exclusivos interesses do mercado, como foi a tônica ao longo da história da educação profissional, mas de qualificá-lo e elevar o seu grau de escolarização, capitais imprescindíveis à efetiva participação na consolidação democrática do país (PACHECO, 2011). Ou seja, os IFs representam as mais novas autarquias de regime especial de base educacional humanístico-técnico-científica, encontrando na territorialidade e no modelo pedagógico elementos singulares para sua definição identitária (OLIVEIRA; ESCOTT, 2015). Nota-se estreita relação dos IFs com a territorialidade, uma vez que a essas instituições educacionais foi conferido o papel de apoiar a estruturação do desenvolvimento de territórios (MACHADO, 2011). Os IFs, portanto, constituem-se em importante instrumento de aplicação da educação profissional como política pública para o desenvolvimento regional (BRASIL, 2008).

Conforme Machado (2011), essas instituições são orientadas pela busca de transformações sociais a favor da inclusão social e da melhoria do padrão de vida da população dos territórios em que se encontram. A estrutura multicampi dos IFs busca atender à vocação regional, consolidando a missão dessas instituições voltadas ao compromisso de intervenção em suas respectivas regiões, identificando problemas e criando soluções. Para tanto, as políticas públicas indicam que a criação de cursos novos deve ser definida por meio de audiências públicas com a participação e a manifestação da sociedade (PACHECO, 2011). Ou seja, passa a ser fundamental a realização de rigoroso diagnóstico que permita identificar as necessidades educativas, contemplando as especificidades regionais (KUENZER, 2010).

Além disso, observa-se que a estruturação dos IFs, com Reitorias, campi nas cidades-polo e campi avançados cobrindo regiões afastadas dos grandes centros, busca alavancar o desenvolvimento regional. Articulados nos eixos ensino, pesquisa e extensão, os IFs têm como objetivo preparar os egressos para o mundo do trabalho, mas também para a inserção social. A interiorização dos IFs poderá contribuir de forma significativa com a redução das desigualdades sociais e disparidades regionais e possibilitar o diálogo entre as esferas municipal, estadual e federal (PALMA; ALVES; SILVA, 2013). Desse modo, na construção de suas identidades institucionais, os IFs estão desafiados a identificar as parcerias estratégicas, a mobilizar ativos locais e a incorporar todos os aspectos das mesorregiões em que se situam (MACHADO, 2011). 
Apesar, no entanto, de a expansão da RFEPCT ter representado grande avanço no cenário nacional, ela ocorreu de forma muito acelerada, causando uma aparente desestruturação nos IFs. Em uma primeira avaliação da expansão é possível perceber uma série de pontos fracos, entre os quais se destaca, principalmente, a deficiência de estrutura física (ANDRADE, 2014). Nessa linha, Schwartzman e Castro (2013) defendem que se constitui grande problema ancorar toda a nova política de educação profissional nos recém-criados IFs, especialmente considerando que essas instituições vêm abandonando sua missão principal, a formação técnica de nível médio, para adotar atividades de mais prestígio, como a pesquisa e a educação superior. Ciavatta (2006) já alertava que a concessão do status de universidade aos IFs poderia levar à tendência de aumento na oferta de cursos superiores, em detrimento dos cursos técnicos de nível médio, por uma questão de demanda e de prestígio.

Há de se considerar que a modalidade foco de atuação dos IFs é o ensino técnico de nível médio, prioritariamente na modalidade integrada, observando-se que no mínimo 50\% de suas vagas devem ser destinadas para tal (BRASIL, 2008), portanto, o aumento da oferta de cursos superiores nestas instituições, em detrimento à oferta de cursos técnicos de nível médio, precisa ser analisado com cautela, considerando que grande parte dos jovens que procuram essas instituições não o fazem pela formação técnica que oferecem, mas pela alta qualidade de seu Ensino Médio integrado, o que é visto por esses jovens como uma oportunidade de acesso facilitado ao Ensino Superior público, por possibilitarem melhores resultados no Enem (KUENZER, 2010).

\section{PROCEDIMENTOS METODOLÓGICOS}

A pesquisa teve abordagem predominantemente qualitativa. Como método foi adotado o estudo de caso único, conforme preconizado por Yin (2010), com múltiplas unidades de análise constituídas pelos três campi do IFSC instalados no sul do Brasil, região Oeste Catarinense: Chapecó, São Miguel do Oeste e Xanxerê.

Este estudo de caso relacionado ao IFSC merece atenção porque são justamente estes institutos que, majoritariamente, constituem a RFEPCT, e a realização do estudo pode contribuir para maior entendimento da relevância da educação profissional para o contexto regional, sobretudo para o seu desenvolvimento. A escolha pelo IFSC embasou-se no recorte regional selecionado como lócus de pesquisa, ou seja, a região Oeste Catarinense.

Em relação à coleta de dados, inicialmente foi realizada pesquisa bibliográfica seguida de pesquisa documental, em fontes legais e institucionais do IFSC (Lei 11.892/2008, Resolução CNE/CEB 6/2012, Lei 13.005/2014 e Plano de Desenvolvimento Institucional - PDI). Partiu-se então para a pesquisa de campo, sendo utilizadas três técnicas de coletas de dados: entrevistas, observação e questionários. As entrevistas foram aplicadas com agentes internos e externos ao IFSC. No grupo de agentes internos foram entrevistados o reitor do IFSC e o diretor de cada um dos campi envolvidos, enquanto no grupo de agentes externos foram entrevistados o prefeito de cada um dos municípios envolvidos e o secretário de Desenvolvimento Regional de cada uma das regionais envolvidas. A observação foi realizada concomitantemente às entrevistas. Os questionários foram aplicados aos egressos e aos servidores de cada um dos campi pesquisados. 
As entrevistas foram gravadas mediante a autorização dos entrevistados e posteriormente transcritas. A observação foi realizada nos campi do IFSC estudados, com as impressões e observações dos pesquisadores sendo convertidas em notas de campo (NC). Os questionários foram estruturados no Google Docs e enviados via e-mail para 220 servidores e 414 egressos. Os questionários foram encaminhados para a totalidade dos servidores e egressos dos três campi pesquisados. Observa-se que o quantitativo total de egressos dos três campi era de 914, porém 201 deles não possuíam endereço de e-mail cadastrado no IFSC, não sendo possível o encaminhamento do link da pesquisa para eles. Dessa forma, foi enviado o e-mail com o link do questionário para 713 egressos, no entanto 132 e-mails retornaram com mensagem de erro, indicando que a conta não se encontrava mais ativa. Assim sendo, 581 egressos receberam de fato o e-mail. Destes 581 egressos, 167 não tinham contas de e-mail pessoais cadastradas no IFSC, mas uma conta de e-mail criada pelo próprio IFSC e que era utilizada pelo egresso enquanto ainda era aluno, ou seja, a probabilidade de que o egresso não acesse mais este e-mail após a conclusão do curso é grande, portanto restaram 414 egressos com maior probabilidade de terem tido acesso ao e-mail com o link do questionário. Desse modo, este quantitativo foi considerado para fins de cálculo da taxa de resposta.

Dos 220 servidores que receberam o e-mail com o link da pesquisa, 48 responderam ao questionário, o que corresponde a uma taxa de resposta de aproximadamente $22 \%$. Em relação aos egressos, dos 414 que receberam o e-mail com o link da pesquisa, 76 responderam ao questionário, o que corresponde a uma taxa de resposta de aproximadamente $18 \%$. Esse quantitativo de retorno pode ser considerado razoável (MARCONI; LAKATOS, 2005). Ademais, não se objetivou atender a normas estatísticas nesta pesquisa, haja vista o seu caráter qualitativo, no qual se buscou captar a percepção dos sujeitos. A defasagem no cadastro dos egressos junto ao IFSC representa importante achado de pesquisa, uma vez que se constatou que o relacionamento com os egressos não é efetivo neste Instituto.

No que se refere à análise dos dados, iniciou-se aplicando a técnica de triangulação de dados, a fim de realizar a confrontação das informações obtidas, analisando-as à luz da fundamentação teórica do estudo (OLIVEIRA, 2010). Para o tratamento e análise de dados foi utilizada a Análise de Conteúdo, conforme apregoa Bardin (2011). A Análise de Conteúdo contemplou as fases de pré-análise, exploração do material e tratamento dos resultados. A maioria dos procedimentos da Análise de Conteúdo organiza-se por meio de categorias de análise, que consistem na classificação e agrupamento de elementos (unidades de registro). Como categorias de análise, emergentes da revisão bibliográfica do estudo, adotaram-se: Desenvolvimento Regional; Educação Profissional e Educação Profissional Para o Desenvolvimento Regional. Essas categorias, estabelecidas a priori com base na revisão bibliográfica, foram revisadas a partir do seu cotejamento com os dados, especialmente, nos seus desdobramentos e descritores.

\section{ANÁLISE DOS RESULTADOS}

Os entrevistados foram identificados inicialmente pela letra " $E$ ", que faz alusão ao termo "Entrevistado", seguido de um número de controle, indo de Entrevistado 1 (E1) até Entrevistado 10 (E10). Do E1 ao E4 foram agentes internos e do E5 ao E10 fo- 
ram agentes externos. Quanto aos respondentes dos questionários, foram inicialmente identificados pela letra " $R$ ", que faz alusão ao termo "Respondente", seguido da letra de identificação do grupo ao qual pertence: " $E$ " para os egressos e " $\mathrm{S}$ " para os servidores, seguido do número de ordem em que respondeu o questionário. Assim sendo, para os servidores vai de RS1 até RS48, e para os egressos vai de RE1 até RE76.

$\mathrm{Na}$ análise documental evidenciou-se que o compromisso do IFSC com o desenvolvimento regional já é trazido pela própria Lei de criação dos IFs (Lei 11.892/2008), bem como pela Resolução CNE/CEB 6/2012 e reforçado pelo Plano Nacional de Educação PNE (Lei 13.005/2014), este, notadamente, o principal fim para o qual tais instituições foram criadas. Conforme apregoa Machado (2011), o processo de desenvolvimento regional somente se consolida por meio da articulação entre os diversos atores territoriais, tanto públicos quanto privados, o que é reconhecido pelo próprio IFSC em seu PDI, quando afirma que "a aproximação do IFSC com os diversos atores da sociedade qualifica o ensino e impulsiona as atividades de pesquisa e de extensão, ampliando a captação de recursos financeiros e permitindo que o IFSC atenda às demandas da sociedade" (IFSC, 2014, p. 280). Um desses atores, e que no caso da educação profissional ganha especial destaque, diz respeito às empresas. O IFSC demonstra buscar essa aproximação com o setor empresarial, conforme E1: "Nós procuramos ter uma interação muito grande com as empresas, tanto que nos nossos colegiados a gente tem representação [...]: ou empresários ou associações comerciais [...], isso traz possibilidades de a gente fazer essa interação". A articulação entre o IFSC e as empresas é feita principalmente por meio de parcerias, conforme E1: "Vamos fazer uma parceria, vamos apoiar onde tem realmente um projeto, um problema da empresa para resolver".

A articulação com as empresas torna-se necessária no modelo de educação profissional devido à necessidade da formação de parcerias visando à realização de estágios. A preocupação com essa questão pode ser observada no PDI do IFSC: "Deve-se [...] buscar articulação e parcerias com empresas para a oferta de estágios [...]" (IFSC, 2014 , p. 70). Apesar, no entanto, de o IFSC reconhecer a importância do estágio, observa-se pela análise do PDI que as políticas de estágio ainda estão em fase de construção: “Construção da política e regulamento de estágio: na concepção do estágio como prática educativa [...]" (IFSC, 2014, p. 193). O IFSC trata a construção de política e regulamentação de estágio como uma inovação no processo educativo, o que revela que ainda não há a prática institucionalizada do estágio dentro da instituição. Esse resultado fica evidenciado na fala do E4: "Tivemos vínculos de estágios já com empresas, agora no momento não, porque nós não temos aluno estagiário; o nosso estágio é não obrigatório". Tendo em vista a importância do estágio para a formação profissional, esse ponto é preocupante, pois evidencia que o IFSC trabalha com estágios não obrigatórios, ou seja, podem incorrer no risco de formar profissionais sem a devida prática necessária para o exercício profissional.

Outro ponto fundamental a ser abordado no que diz respeito à articulação do IFSC com os atores territoriais refere-se à articulação com os demais órgãos públicos da região, especialmente das esferas municipal e estadual, uma vez que a articulação entre os diferentes níveis de governo é importante elemento para a consolidação do processo de desenvolvimento regional, conforme sustentam Palma, Alves e Silva (2013). A articulação do IFSC com as demais organizações públicas da região também ocorre por meio 
de parcerias, conforme E1: "Nós fizemos várias parcerias por conta dos projetos da Educação a Distância. Então nós temos com a prefeitura, [...] convênios com essa parceria em que eles têm o polo [...] e o Instituto dá o curso, então isso é muito bom. Temos convênios também com o Estado [...]".

O participante enfatiza primeiramente a questão da parceria com a prefeitura, que é viabilizada por meio da Universidade Aberta do Brasil (UAB), um projeto desenvolvido pelo MEC para ampliar o acesso à educação superior, e que entre seus principais objetivos visa a promover maior aproximação das instituições de ensino e dos governos municipais e estaduais, no entanto, apesar de constituir importante parceria, trata-se de um programa federal, conforme E9: "[...] outra parceria que nós temos com eles [IFSC], [a gente] mantém um colégio aqui através da UAB. E tem cursos que eles é que estão fazendo, isso é muito bom também né, mas é um convênio federal".

Nos resultados da pesquisa observou-se que as parcerias entre o IFSC e os municípios e/ou Estado são tímidas e, em muitos casos, inexistentes, conforme falas dos agentes externos: "Hoje não [temos parceria com o IFSC], mas, nós gostaríamos de ter" (E8). "Não, não temos nenhuma parceria firmada [com o IFSC]. Não temos diretamente essa relação" (E10). Percebe-se, na fala do E8, que apesar de manifestar interesse em ter uma parceria com o IFSC, esta ainda não existe, o que pode significar falta de interesse por parte do próprio Instituto em fechar estas parcerias com os órgãos públicos, ideia esta que é reforçada pelo E9: "[...] também tem que ser do lado deles [IFSC] uma busca $[\ldots]$, tem que agir, não é só nós correr atrás, eles também têm que correr atrás [...]". 0 E10 manifestou não ter parcerias firmadas com o IFSC, mas, ao justificar esta questão, assim se posicionou: "[...] também relaxei, nunca busquei mais detalhes [a respeito do IFSC]". Ou seja, o agente externo também assume a responsabilidade pela ausência de parcerias com o IFSC.

Conforme se pode observar na fala do E3, existe dificuldade em se manter integração maior e duradoura com o poder municipal: “[...] a gente tem um pouco de dificuldade nessa relação com o poder público municipal. Por que, antes do Instituto [se instalar], existe uma movimentação muito grande dos municípios, mas depois que o Instituto [se instala] nem sempre essa relação continua". De fato, pode-se observar que os munícipios fazem bastante questão de sediarem os campi do IFSC, sendo comum, inclusive, a doação de terrenos por parte das prefeituras para que o IFSC construa suas instalações, conforme E8: "A prefeitura doou o terreno para o Instituto Federal. O Instituto Federal fez a sua obra, investiu. Hoje é então esta unidade que capacita muito, é uma vitória para a região [...]", no entanto esse interesse em sediar os campi do IFSC por parte dos municípios parece ser mais de ordem política do que social, pois, do contrário, o relacionamento entre a instituição e o poder público municipal perduraria e até se intensificaria após a instalação do campus.

Conforme argumentam Palma, Alves e Silva (2013), para que o IFSC possa contribuir de maneira efetiva com o desenvolvimento regional é necessário que todas suas atividades estejam articuladas em três eixos: ensino, pesquisa e extensão. Por meio da análise documental, identificou-se que o IFSC apresenta preocupação com essa questão em seu PDI, entretanto restou evidenciado que o IFSC é eficiente na atividade de ensino, mas ainda deficiente nas atividades de pesquisa e extensão, conforme E3: "[...] quando os IFs foram criados a ideia de pesquisa e extensão não é a mesma ideia das Universida- 
des. Nós temos uma dificuldade de entender o nosso papel dentro da pesquisa e da extensão. O ensino hoje é a parte que nós conseguimos ser referência". Essa fala, além de confirmar o ensino como a principal competência do IFSC, apresenta o principal entrave pelo qual a pesquisa e a extensão não estão consolidadas dentro da instituição: trata-se do sombreamento da modalidade acadêmica, o que ainda é uma questão recorrente no Brasil (KUENZER, 2010).

Buscando aprofundar essa discussão foi questionado aos egressos se durante o curso realizaram alguma outra atividade no IFSC além das aulas, destacando-se que $70 \%$ responderam que "Não" e apenas 30\% responderam que "Sim." Os que disseram que realizaram alguma outra atividade assim se posicionaram: declararam ter participado de projetos de extensão (RE11 e RE20), ter participado de projetos de pesquisa (RE2; RE3; RE4; RE6; RE7; RE8; RE10; RE13; RE36; RE41; RE53 e RE59) e expuseram ter participado de estágios (RE33 e RE43). A pesquisa, apesar de ainda ocorrer de forma tímida no IFSC, mostra-se mais consolidada do que a atividade de extensão.

Trata-se de um resultado relevante, uma vez que considerando a função social do IFSC, a atividade de extensão ganha destaque e, portanto, deveria ser mais fortemente trabalhada dentro da instituição, por permitir maior aproximação com a comunidade e o meio social de convívio de seus alunos, contribuindo com sua formação, conforme a própria instituição prevê em seu PDI: "As atividades de extensão são extremamente importantes para a formação integral do aluno, uma vez que estão intrinsecamente relacionadas com o seu contexto social, econômico e cultural" (IFSC, 2014, p. 44). Esse é o primeiro indicativo de um aparente desvio de função por parte do IFSC, que é discutido com maior profundidade ao longo das análises, e que vem ao encontro do que apregoam Ciavatta (2006) e Schwartzman e Castro (2013).

Outra percepção a ser destacada foi em relação à educação profissional no Brasil, conforme E3: "[...] nós [Brasil] ainda temos preconceito com a Educação Profissional, isso é fruto de uma história de desvalorização de quem trabalha no braçal, e tem um valor maior quem faz um trabalho intelectivo. E é claro que isso foi incorporado na nossa cultura". Aliás, esse preconceito para com a educação profissional parece ser reforçado pelo próprio governo, que apesar de no discurso reconhecê-la como importante, na prática dificulta o caminho de quem opta por seguir seu percurso formativo pela via profissional. Conforme explicitam Oliveira e Viana (2012), essa modalidade de educação integra um sistema paralelo ao regular, prova disso é a configuração do Ensino Médio, que obriga os alunos a cursarem um conjunto idêntico de disciplinas, que visam a preparar para o acesso ao Ensino Superior (SCHWARTZMAN; CASTRO, 2013). A promulgação da Lei 13.415/17, que trata da reforma do Ensino Médio, parece uma tentativa de corrigir essas questões, no entanto ainda é cedo para saber se essa mudança promoverá, de fato, a efetivação do Ensino Médio integrado ou se institucionalizará de vez a dualidade estrutural no sistema educacional brasileiro.

Emerge também das falas dos participantes a questão da visão reducionista que se tem da educação profissional, considerando-a apenas como uma formação para o mercado de trabalho. Conforme E1: "[...] acho que existe uma dicotomia na Educação Profissional 'Ah, é uma formação de mão de obra', então se fazem algumas analogias com aquela pessoa que não vai pensar, que vai só executar, que vai só reproduzir". Nota-se nesse discurso o levantamento de uma discussão importante e que reflete a di- 
cotomia existente entre educação acadêmica e profissional no Brasil, cabendo à modalidade acadêmica a formação dos pensadores, para atuarem nas funções táticas e estratégicas, e à modalidade profissional a formação dos executores, para atuarem nas atividades operacionais.

Essa visão pode ser observada também nas falas dos servidores respondentes dos questionários ao conceituarem a educação profissional: "Educação que prepara para o mercado de trabalho". (RS1; RS2; RS14; RS17; RS19; RS30; RS35; RS38; RS44). "Educação focada nas atividades operacionais em empresas". (RS36). Observa-se que ao conceituarem a educação profissional, os participantes a relacionam majoritariamente à formação de mão de obra para o mercado de trabalho. Nota-se que essa visão é compartilhada pelos agentes externos entrevistados que, ao serem questionados quanto à educação de uma forma geral, imediatamente passam a fazer menção à modalidade acadêmica e somente se posicionam quanto à educação profissional ao serem questionados especificamente sobre essa modalidade, voltando imediatamente os seus comentários ao atendimento das necessidades do mercado de trabalho: "A Educação Profissional é fundamental, por que as empresas exigem mão de obra qualificada. $O$ Instituto forma a mão de obra qualificada, que é um curso mais rápido e que qualifica a pessoa para o mercado de trabalho" (E7).

Esse resultado é reforçado quando se questiona os egressos quanto à sua renda. A maioria deles (84\%) tem renda de até quatro salários mínimos, o que é complementado pela manifestação dos egressos quanto às atividades desenvolvidas em seu trabalho atual, uma vez que $71 \%$ desenvolvem atividades técnico-operacionais e apenas $29 \%$ desenvolvem atividades técnico-administrativas, em níveis tático e estratégico. Evidencia-se, assim, que a prática da educação profissional no Brasil ainda se reduz à qualificação de mão de obra para o mercado de trabalho, por meio de cursos técnicos de nível médio. Ou seja, mesmo com o advento nos anos 70 dos cursos superiores de tecnologia e, mais recentemente, dos Mestrados Profissionais, o curso técnico de nível médio continua sendo a modalidade foco da educação profissional no Brasil, isso porque essa modalidade ainda sofre com os sombreamentos da modalidade acadêmica e com os preconceitos históricos que lhes foram atribuídos e incorporados à cultura brasileira (KUENZER, 2010; TAKAHASHI, 2010).

Além da questão cultural, restou evidenciado que contribui para o atual cenário da prática da educação profissional no país a forma acelerada como ocorreu a expansão da RFEPCT, o que vem ao encontro do que defende Andrade (2014). Essa questão fica evidenciada na fala do E1: "[...] são nove anos que nós começamos a expansão. Nós passamos de 3 campi para 22 [...]. A gente passou por uma expansão muito grande". Fica claro como a expansão ocorreu de forma acelerada, quando o IFSC passou, em apenas nove anos, de 3 para 22 campi, um crescimento de 633\%. Crescimento tão expressivo percebido também pelos agentes externos, conforme E7: "O IFSC está crescendo bastante. A gente acompanha dentro das possibilidades".

A forma como ocorreu a expansão da RFEPCT ocasionou sérios problemas de estrutura física ao IFSC, o que levou a instituição a elencar em seu PDI uma série de critérios para definir as prioridades de infraestrutura. Essa problemática é reconhecida pelos agentes internos, conforme E4: “[...] a nossa estrutura física é hoje o nosso maior problema”. E também pelos agentes externos, conforme E6: “[...] o Instituto hoje preci- 
sa ser ampliado porque ele já está pequeno". Na observação constatou-se que os campi ainda carecem de estrutura física mais adequada, principalmente de laboratórios de prática, mas também de salas de aula, de professores e para as atividades administrativas.

Essa expansão acelerada da rede, com a instalação de novos campi em detrimento da consolidação dos já existentes, culminou com a criação de campi, em algumas localidades, visando a atender pressões políticas e não demandas sociais. Esse aspecto pode ser observado na fala do E2: “[...] na Região Oeste de Santa Catarina foi um movimento envolvendo municípios, deputados, senadores que são da região e fizeram um trabalho grande para trazer esses campi para a região". Não se está alegando que a região não seja merecedora de ter os campi do IFSC. A discussão em questão trata da interferência política no processo de instalação dos campi, sem que seja realizado estudo técnico da viabilidade dessa instituição, bem como uma ampla discussão com as comunidades receptoras desses investimentos públicos. Essa discussão vai, inclusive, para além da localidade de estabelecimento dos campi, pois seria mais efetivo primeiramente buscar a consolidação plena daqueles já existentes, para então começar a pensar na criação de novos campi, o que parece ser reconhecido pelos agentes internos, conforme E2: "[...] eu vejo que a nossa expansão poderia ter sido feita com mais cautela, [...] poderia ter sido um pouco menos acelerada e melhor estruturada".

Além disso, a expansão acelerada não permitiu que houvesse tempo para a realização de pesquisas efetivas que permitissem a abertura de cursos alinhados às necessidades do desenvolvimento regional (ANDRADE, 2014). Por meio da análise documental, constatou-se que a lei de criação dos IFs apregoa que esta é uma premissa básica dessas instituições, na linha do que defende Pacheco (2011). Essa preocupação em atender às demandas regionais pode também ser observada no PDI do IFSC e também na fala dos agentes internos: "[...] a ideia é que se faça contato, que se tenha esse diálogo com a comunidade. A elaboração dos cursos, os projetos pedagógicos, surgem das demandas da comunidade". (E4). Ou: "Os cursos do IFSC são, em geral, demandas que a população votou em audiência pública". (RS3).

Apesar, no entanto, dos esforços envidados pelo IFSC para adequar suas ofertas às demandas regionais, nota-se que os agentes externos não consideram que os cursos atendam às necessidades formativas da região: "Eu penso que teria que fazer uma pesquisa de mercado e sentir aquilo que realmente está necessitando para atender às demandas que hoje estão no dia a dia das atividades econômicas da região". (E7). Esse resultado é reforçado pelo RS24: "Os cursos ofertados deveriam atender às demandas atuais e/ou impulsionar o desenvolvimento de outras atividades potenciais. Mas os cursos são os mesmos sempre, e não observam mudanças de demandas ou procura".

Outro resultado relevante diz respeito à constatação, por meio da análise do PDI, de que o IFSC vem diminuindo gradativamente a oferta de cursos técnicos de nível médio e aumentando a de cursos superiores, na linha do que alertam Ciavatta (2006) e Schwartzman e Castro (2013). Ou seja, mesmo que a lei de criação dos IFs estabeleça que sua modalidade foco é o ensino técnico de nível médio, observando-se que $50 \%$ das vagas devem ser reservadas para tal, a instituição vem diminuindo essa oferta. No ano de 2015 a oferta de cursos técnicos de nível médio pelo IFSC representava $66 \%$ do quantitativo total de vagas; 2016 passou para 61\%, em 2017 para 59\%, em 2018 para 
57\% e em 2019 para 56\%, ou seja, diminuição de 10\% em relação a 2015. Quanto à oferta de cursos superiores, em 2015 estes representavam 23\% do quantitativo total de vagas, em 2016 subiu para 25\%, em 2017 para 28\%, em 2018 para 30\%, e em 2019 para $32 \%$, ou seja, aumento de $9 \%$ na oferta em relação a 2015. Esse aspecto aponta que o IFSC vem aumentando a oferta de ensino superior em detrimento da proposição de cursos técnicos.

Embora os próprios agentes internos tenham a percepção de que a oferta de cursos superiores não é a missão do IFSC, conforme E4: "[...] a ideia dos Institutos não era que eles fossem para o ensino superior. Mas do ingresso de 2015 para 2016 aumentou $51 \%$ a oferta de cursos superiores no Instituto Federal, porque é a demanda". Considerando que a modalidade foco do IFSC é o curso técnico de nível médio, há de se destacar que, em geral, em nenhum momento a oferta dessa modalidade mostra-se inferior ao mínimo de $50 \%$ estabelecido pela legislação, embora venha diminuindo gradativamente com a intenção de se manter apenas o mínimo determinado. Considera-se legítimo o anseio da população em galgar o Ensino Superior, o que se questiona neste estudo é se os IFs seriam o melhor instrumento para a efetivação dessa demanda ou se eles teriam outra missão tão relevante quanto prover o acesso à educação superior. Importante considerar que os cursos técnicos de nível médio e os cursos superiores podem se beneficiar e se fortalecer mutuamente, possibilitando a otimização de professores, laboratórios, entre outros, desde que se encontrem dentro do mesmo eixo-formativo.

Esse resultado, no entanto, que aponta para o aumento dos cursos superiores em detrimento da oferta de cursos técnicos, somado ao resultado de que a maioria dos alunos que ingressa no curso técnico integrado o faz pela qualidade do Ensino Médio e não pela formação profissional, pode significar um aparente desvio de função por parte do IFSC, que vai além de a pesquisa estar mais difundida na instituição do que a extensão, uma vez que este deixa de promover a inserção profissional de seus egressos, importante função social que Ihe foi atribuída, e passa a prepará-los para o acesso ao Ensino Superior, na linha do que defende Kuenzer (2010). Pode-se observar essa situação no depoimento do E4: "[...] as pesquisas mostram, dos alunos que vêm, $10 \%$ querem ser técnicos em alimentos, técnico em informática, eles não vão ser técnicos, eles vêm pelo ensino médio. O que foge dessa ideia da criação [do IFSC] [...]."

Por essa razão, o aumento dos cursos superiores no IFSC em detrimento à oferta de cursos técnicos precisa ser analisado com cautela, pois apesar de essas duas modalidades de cursos poderem se beneficiar e se fortalecer entre si, há de se considerar a possibilidade de um aumento de oferta de cursos superiores por uma razão de demanda e de prestígio, na linha do que argumentam Ciavatta (2006) e Schwartzman e Castro (2013). Essa questão fica evidenciada na fala do E3: "Agora estamos [no IFSC] com curso superior e técnico. Quando coloca os dois à disposição, o superior atrai muito mais pelo prestígio que [o curso superior] ainda traz pra nós". Fica nítida a preferência dos estudantes brasileiros pelo Ensino Superior, o que se deve principalmente à questão cultural, pois no Brasil estabeleceu-se a ideia de que ser detentor de um grau superior confere um status maior ao indivíduo. Dessa forma, esta prática de aumento na oferta dos cursos superiores em detrimento aos cursos técnicos parece remeter mais à submissão do IFSC às demandas de mercado e aos contornos culturais brasileiros do que à prática 
que vise a consolidar uma cultura favorável à educação profissional de qualidade e que permita aos seus egressos atuação profissional sólida, gerando melhores condições de vida e contribuindo para o desenvolvimento regional.

\section{CONSIDERAÇÕES FINAIS}

A partir do objetivo de analisar a atuação dos IFs e a sua adesão ao papel da EPT de promoção do desenvolvimento regional, verificou-se que os resultados da pesquisa apontam para a relevância do papel da EPT, que é tratada como uma importante política pública voltada para o desenvolvimento regional, tendo ganhado destaque na legislação educacional no Brasil desde a promulgação da LDB (Lei 9.394/1996), e com maior ênfase a partir da edição da Lei 11.892/2008, que instituiu a RFEPCT e criou os IFs, perpassando pela Resolução CNE/CEB 6/2012 e culminando com a promulgação do PNE (Lei 13.005/2014), papel este que é reconhecido pelo IFSC em seu PDI.

Verificou-se, no entanto, que, na prática, o IFSC ainda não conseguiu se consolidar como uma ferramenta de aplicação da EPT como política pública voltada ao desenvolvimento regional, o que se deve, principalmente, às marcas culturais brasileiras que destinam à educação profissional um papel menor na carreira, o que acabou incorporando-se à cultura interna da instituição, bem como à forma acelerada como ocorreu a expansão RFEPCT no país, questões essas que reduzem a contribuição dos IFs à qualificação de mão de obra para o mercado de trabalho, sobretudo por meio da EPTNM. Além disso, identificou-se, por parte do próprio IFSC, um aparente desvio de função em relação à finalidade para a qual foi criado. Essa percepção restou evidenciada ao constatar-se que a instituição deixa de promover a inserção profissional de seus egressos e passa a prepará-los para o acesso ao Ensino Superior. Soma-se a esse resultado o fato de que o IFSC vem aumentando a oferta de cursos superiores em detrimento à oferta de cursos técnicos, bem como vem desenvolvendo de forma mais sólida as atividades de pesquisa do que as de extensão.

Diante desse cenário, conclui-se que cabe ao IFSC um papel estratégico, porém árduo, tendo em vista que perpassa pela mudança de cultura, sobretudo na forma como a prática da educação profissional é encarada no Brasil. Não há de se esperar, contudo, que um contorno cultural moldado em mais de cinco séculos mude em poucas décadas; é possível que sejam necessários mais outros tantos séculos para consolidar essa mudança, porém é necessário iniciar esse movimento de transformação, o que não ficou evidenciado nos resultados da pesquisa, uma vez que ficou demonstrado que o IFSC vem se moldando aos contornos culturais brasileiros, ao invés de buscar modificá-los.

Salienta-se que este estudo teve como contribuição um olhar mais apurado sobre três campi do IFSC na região Oeste de Santa Catarina, embora, como limitação, não seja possível generalizar os resultados aqui apresentados para outras instituições, nem mesmo para os demais campi do IFSC inseridos em outro contexto regional. Como recomendação de novos estudos sugere-se a abordagem comparativa de outros IFs, bem como dos campi do IFSC inseridos em outras regiões, para propiciar uma visão mais ampliada. Seria interessante também realizar estudos no intuito de analisar os resultados da reforma do Ensino Médio, especialmente da integração da educação profissional ao currículo desse nível de formação, bem como dos reflexos dessa reforma nos IFs. 


\section{REFERÊNCIAS}

ANDRADE, A. A expansão dos Institutos Federais: causas e consequências. Dissertação (Mestrado) - Universidade Cidade de São Paulo, São Paulo, 2014.

BANDEIRA, P. S. As mesorregiões no contexto da nova política federal de desenvolvimento regional: considerações sobre aspectos institucionais e organizacionais. Porto Alegre: Universidade Federal do Rio Grande do Sul, 2004.

BARDIN, L. Análise de conteúdo. São Paulo: Edições 70, 2011.

BERNARDY, R. J et al. Apresentação dos indicadores de desenvolvimento sustentável das mesorregiões do Estado de Santa Catarina - Brasil. Revista Iberoamericana de Estudios Municipales, n. 13, p. 9-40, 2016.

BOISIER, S. Em busca do esquivo desenvolvimento regional: entre a caixa-preta e o projeto político. Planejamento e Políticas Públicas, Brasília, n. 13, p. 112-147, 1996.

BRASIL. Lei n. 9.394, de 20 de dezembro de 1996. Lei de Diretrizes e Bases da Educação. Diário Oficial da União, Brasília, DF, 1996.

BRASIL. Lei n. 11.892, de 29 de dezembro de 2008. Institui a Rede Federal de Educação Profissional, Científica e Tecnológica, cria os Institutos Federais de Educação, Ciência e Tecnologia e dá outras providências. Diário Oficial da União, Brasília, DF, 2008.

BRASIL. Lei n. 13.005, de 25 de junho de 2014. Aprova o Plano Nacional de Educação - PNE e dá outras providências. Diário Oficial da União, Brasília, DF, 2014.

BRASIL. Lei n. 13.415, de 16 de fevereiro de 2017. Altera a Lei n. 9.394, de 20 de dezembro de 1996, que estabelece as diretrizes e bases da educação nacional e dá outras providências. Diário Oficial da União. Brasília, DF, 2017a.

BRASIL. Ministério da Educação. Expansão da Rede Federal de Educação Profissional, Científica e Tecnológica. Brasília, DF. Disponível em: http://redefederal.mec.gov.br/expansao-da-rede-federal. Acesso em: 10 fev. 2017c.

BRASIL. Ministério da Educação. Resolução CNE/CEB n. 6, de 21 de setembro de 2012. Define Diretrizes Curriculares Nacionais para a Educação Profissional Técnica de Nível Médio. Diário Oficial da União. Brasília, DF, 2012.

BRASIL. Ministério da Educação. Resolução CNE/CP n. 2, de 22 de dezembro de 2017. Institui e orienta a implantação da Base Nacional Comum Curricular, a ser respeitada obrigatoriamente ao longo das etapas e respectivas modalidades no âmbito da Educação Básica. Diário Oficial da União, Brasília, DF, 2017b.

BRASIL. Ministério da Integração Nacional. Política Nacional de Desenvolvimento Regional. Brasília, DF: MI, 2003.

CIAVATTA, M. Os Centros Federais de Educação Tecnológica e o Ensino Superior: duas lógicas em confronto. Educação \& Sociedade, Campinas, v. 27, n. 96, p. 911-934, 2006.

DALLABRIDA, V. R. O desenvolvimento regional: a necessidade de novos paradigmas. ljuí: Editora Unijuí, 2000.

DEITOS, R. A.; LARA, A. M. B. Educação profissional no Brasil: motivos socioeconômicos e ideológicos da política educacional. Revista Brasileira de Educação, v. 21, n. 64, p. 165-188, 2016.

FEGER, J. E. et al. Regionalização: um desafio para o planejamento estratégico do desenvolvimento. Informe Gepec, Toledo, v. 14, n. 2, p. 112-128, 2010.

FILIPPIM, E. S. et al. Cooperação transfronteiriça para o desenvolvimento regional. Desenvolvimento em Questão, ljuí: Editora Unijuí, a. 12, n. 26, p. 5-40, 2014.

GOMES, C. A.; VASCONCELOS, I. C. O.; COELHO, S. R. S. Ensino Médio: nem patinho feio nem cisne? In: GOMES, C. A.; VASCONCELOS, I. C. O.; COELHO, S. R. S. Ensino Médio: impasses e dilemas. Brasília: Cidade Gráfica Editora, 2018. p. 37-77.

IFSC. Instituto Federal de Santa Catarina. Plano de Desenvolvimento Institucional. Florianópolis, 2014.

INEP. Instituto Nacional de Estudos e Pesquisas Educacionais Anísio Teixeira. Entendendo a educação profissional. Brasília, DF: Inep, 2011.

KUENZER, A. Ensino Médio no Plano Nacional de Educação 2011-2020: superando a década perdida? Educação \& Sociedade, Campinas, v. 31, n. 112, p. 851-873, 2010.

MACHADO, L. S. Saberes profissionais nos planos de desenvolvimento de Institutos Federais de Educação. Cadernos de Pesquisa, v. 4, n. 143, p. 352- 375, 2011.

MARCONI, M. A.; LAKATOS, E. M. Fundamentos de metodologia científica. 6. ed. São Paulo: Atlas, 2005. 
MELLO, S. P. T.; MELO, P. A.; MELLO FILHO; R. T. Competências gerenciais evidenciadas e desejadas dos integrantes do Fórum de Gestão de Pessoas da Rede Federal de Educação Profissional, Científica e Tecnológica. Revista de Administração, Contabilidade e Economia, Joaçaba: Ed. Unoesc, v. 15, n. 1, p. 349-374, 2016.

MORENO, L. A. La Década de América Latina y el Caribe: una oportunidad real. 2. ed. Washington: BID, 2011.

MOURA, D. H. Ensino Médio integrado: subsunção aos interesses do capital ou travessia para a formação humana integral? Educação e Pesquisa, São Paulo, v. 39, n. 3, p. 705-720, 2013.

OLIVEIRA, A. R. M.; ESCOTT, C. M. Políticas públicas e o ensino profissional no Brasil. Ensaio: Avaliação e Políticas Públicas em Educação, Rio de Janeiro, v. 23, n. 88, p. 717-738, 2015.

OLIVEIRA, M. M. Como fazer pesquisa qualitativa. 3. ed. Petrópolis: Vozes, 2010.

OLIVEIRA, M. R. N. S.; VIANA, I. C. Políticas de Educação profissional no mundo globalizado: o caso brasileiro. Trabalho \& Educação, Belo Horizonte, v. 21, n. 2, p.43-62, 2012.

PACHECO, E. M. Institutos Federais: uma revolução na educação profissional e tecnológica. Brasília, DF: Fundação Santillana; São Paulo: Moderna, 2011.

PALMA, L. C.; ALVES, N. B.; SILVA, T. N. Educação para a sustentabilidade: a construção de caminhos no Instituto Federal de Educação, Ciência e Tecnologia do Rio Grande do Sul (IFRS). Rev. Adm. Mackenzie, São Paulo, v. 14, n. 3, p. 83-118, 2013.

PORTER, M. Competição: estratégias competitivas essenciais. 4. ed. Rio de Janeiro: Campus, 1999.

SCHWARTZMAN, S. O novo Ensino Médio: o difícil caminho à frente. In: GOMES, C. A.; VASCONCELOS, I. C. O.; COELHO, S. R. S. Ensino Médio: impasses e dilemas. Brasília: Cidade Gráfica Editora, 2018. p. 15-35.

SCHWARTZMAN, S.; CASTRO, C. M. Ensino, Formação profissional e a questão da mão de obra. Ensaio: Avaliação e Políticas Públicas em Educação, Rio de Janeiro, v. 21, n. 80, p. 563-624, 2013.

SECRETARIA DE EDUCAÇÃO PROFISSIONAL E TECNOLÓGICA. Políticas públicas para educação profissional e tecnológica. Brasília, DF: Setec; MEC, 2004.

SOTARAUTA, M. Shared Leadership and Dynamic Capabilities in Regional Development. In: SAGAN, I.; HALKIER, H. Regionalism Contested: institution, society and governance. Ashgate: Cornwall, 2005.

TAKAHASHI, A. R. W. Cursos Superiores de Tecnologia em gestão: reflexões e implicações da expansão de uma (nova) modalidade de ensino superior em administração no Brasil. Rev. Adm. Pública, v. 44, n. 2, p. 385-414, 2010.

THEIS, I. M.; GALVÃO, A. F. A formulação de políticas públicas e as concepções de espaço, território e região. Revista Brasileira de Estudos Urbanos e Regionais, v. 14, n. 2, p. 55-69, 2012.

YIN, R. K. Estudo de caso: planejamento e métodos. 4. ed. Porto Alegre: Bookman, 2010. 